\title{
HEAT EXCHANGER MODEL-BASED DESIGN SUPPORTED BY EXPERIMENTAL ENGINNEERING
}

\author{
Ricardo Caliari ${ }^{1}$, Dietmar Gernand $^{2}$ e Carlos Camargo ${ }^{2}$ \\ ${ }^{1}$ MAHLE Behr Gerenciamento Térmico Brasil Ltda. \\ ${ }^{2}$ MAHLE Metal Leve SA \\ E-mails: ricardo.caliari@br.mahle.com, dietmar.gernand@br.mahle.com, \\ carlos.camargo@br.mahle.com
}

\begin{abstract}
A product development method for heat exchangers based in dimensionless numbers theory is presented as a fast product engineering method. A product performance test bench is necessary to support this development method. It introduces the actual technology for single phase flow heat exchangers validation test bench. The performance tests are composed of heat transfer power and pressure drop characterization. Data acquisition system, control loops and scientific instrumentation are detailed in this paper.

The construction of the test bench and its implementation was made in a multidisciplinary and multicultural team. Specialists from other locations and different suppliers worked together to implement the project. An actual strict test bench validation program is performed to ensure the quality of the data found in the central data base system. Results deviation, repeatability and reproducibility are worldwide controlled.

This work presents the importance of the experimental engineering not just in the validation process, but also as a speed up tool in all product development phases, plant quality assurance and innovative concepts creation.
\end{abstract}

\section{INTRODUCTION}

The product development based on thermodynamic simulation at MAHLE Behr is performed in a proprietary system called BISS (Behr Integrated Simulation System). This system is a model-based design method, which uses mathematic models from the literature and advanced studies. Those models are constructed with Nusselt number $(\mathrm{Nu}$ - to represent the heat transfer performance), PSI number ( $\psi$ - to represent the pressure drop) and Reynolds number ( $R e-$ to represent the fluid flow). Those dimensionless numbers help in the interpretation of the detailed heat exchanger behavior for each specific operating point. At MAHLE Behr, the heat exchanger is defined by two dimensionless functions (Nusselt versus Reynolds and $\psi$ versus Reynolds) to represent each side of the heat transfer, inner and outer sides.

The Ф/NTU-method, largely presented in [1] describes also different mathematical methods and coefficients to evaluate the heat exchanger and the quality of the heat transfer process. Those coefficients are presented here and are used to evaluate the product design and the tested samples. 
The product engineering team is able, with this accurate simulation system, to easily perform 1D simulation for application projects and have a shorter development time during concept definitions. This methodology consists in introducing real dimensions and boundary conditions to the construction systems, obtaining a plausible proposal for a well known product technology and attending the customer application needs.

To support those development methods, a product performance test bench is necessary. This work introduces the actual technology for single phase flow heat exchangers validation test bench. The performance tests are composed of heat transfer power and pressure drop characterization. This machine can acquire real time data, such as temperature, mass flow, pressure and climatic conditions and save them in a central data base. A stable and automatic control is important to guarantee the operating points steady state conditions, essential for the mathematical models application.

The model-based design method, validated through test bench data, is strategic to lead the fast development process. As the new product development time has significantly reduced in latest years, the company had success in optimizing its process with the use of such technologies. The development of a new cooling module for heavy duty application is presented in [7]. The authors show how the simulation system integrated with application experience can conduct the process and significantly reduce the time to market.

\section{SINGLE PHASE FLOW HEAT EXCHANGER THERMODYNAMIC MODEL}

The principle of the simulation of heat exchangers at MAHLE Behr based on the $\Phi / \mathrm{NTU}$ method with dimensionless functions of heat transfer and pressure drop is shortly described in the following paragraphs and deeply discussed in [1] and [2]. The use of this method at MAHLE Behr was described first in the early 70s [4] and largely used since then.

\subsection{Thermodynamic model assumptions}

The used thermodynamic models are based on the following assumptions:

1.1.1. Steady state operation

1.1.2. No sources or sinks of the material flows in the element itself

1.1.3. The only parameter that changes enthalpy of the streams is the heat flux that is transferred. No heat losses to the surroundings, kinetic either potential energies are considered

1.1.4. No mixing of the various material flows in the element

1.1.5. Thermal and hydraulic functions of both sides of the element are known completely

1.1.6. Homogenous distributions of the temperature (and the mass flow) at the inlet cross section

The method based in Thermal Calculation, Hydraulic Calculation and definition of dimensionless number was detailed described in [5] and is summarized here.

\subsection{Thermal Calculation}

The thermal capacity $\mathrm{Q}$ of heat exchanger is defined in [2] by: 
$Q=k F \cdot \Delta \mathrm{T}_{\mathrm{m}}$

Where $k$ is the heat transfer coefficient, $F$ the heat exchange surface and $\Delta \mathrm{T}_{\mathrm{m}}$ is the difference of the average integral values of the inner and outer temperatures. In this case, Index 1: inner side, Index 2: outer side is applicable. On considering the energy balances and due to the definition of the dimensionless temperature ratio $\Phi$, the following equations are derived additionally for both sides.

$Q=-W_{1} \cdot \Delta \mathrm{T}_{1}=W_{1} \cdot \Phi_{1} \Delta \mathrm{T}_{\mathrm{e}}$, where $\Phi_{1}=-\frac{\Delta \mathrm{T}_{1}}{\Delta \mathrm{T}_{\mathrm{e}}}$

and

$Q=W_{2} \cdot \Delta \mathrm{T}_{2}=W_{2} \cdot \Phi_{2} \Delta \mathrm{T}_{\mathrm{e}}$, where $\Phi_{2}=-\frac{\Delta \mathrm{T}_{2}}{\Delta \mathrm{T}_{\mathrm{e}}}$

Where, $\Delta \mathrm{T}=\mathrm{T}_{\text {out }}-\mathrm{T}_{\text {in }}$ is the change in temperature of the fluid flow and $W$ is the heat capacity current of the sides 1 and 2 . The temperature ratios can assume values between zero and one $(0 \leq \Phi \leq 1)$. The greater of both values is described as thermal effectiveness and is an indicator for ascertaining the quality of the heat exchanger. If this is 1 , then the thermal capacity of the heat exchanger cannot be increased anymore.

The deciding factors for the calculation of $\Phi$ are two dimensionless operating characteristic numbers, the number of transfer units $N T U$ and the ratio $R$ of the heat capacity flows,

$\mathrm{R}_{1}=\frac{\mathrm{W}_{1}}{\mathrm{~W}_{2}}$

$\mathrm{NTU}_{1}=\frac{\mathrm{kF}}{\mathrm{W}_{1}}$

being:

$\mathrm{R}_{2}=\frac{\mathrm{W}_{2}}{\mathrm{~W}_{1}}=\frac{1}{\mathrm{R}_{1}} ; \quad \mathrm{NTU}_{2}=\frac{\mathrm{kF}}{\mathrm{W}_{2}}=\mathrm{NTU}_{1} \cdot \mathrm{R}_{1}$

All analytically solved equations for calculating of $\Phi$ are of type

$\Phi=f($ Heat exchanger type, flow type, $N T U, R)$

Where the equation:

$\Phi_{2}=\Phi_{1} \cdot \mathrm{R}_{1}$

must be fulfilled. The equation type depends on the heat exchanger flow type (counter current flow, co-current flow, cross flow etc), which are presented in the [2] and deeply studied by the company specialists.

1.3. Hydraulic Calculation 
The pressure loss $\Delta P$ in heat exchangers consists of frictional pressure losses, $\Delta P_{R}$, change in momentum of the current $\Delta P_{I}$ and turbulences $\Delta P_{W}$ at the inlet and outlet in the heat exchanger matrix,

$\Delta P=\Delta P_{R}+\sum \Delta P_{I}+\sum \Delta P_{W}$

The pressure losses are always based on the mass flow density, $\dot{m}$, in the heat exchanger tube and fluid density, $\rho$. With the following definition, it is possible to obtain the friction factor $\psi$ and the pressure drop coefficient $\varsigma$.

$\Delta P=\frac{\dot{m}^{2}}{2 \rho} \cdot\left(\psi \cdot \frac{L_{h}}{D_{h}}+\sum \varsigma_{I}+\sum \varsigma_{W}\right)$

The hydraulic flow path $\mathrm{L}_{\mathrm{h}}$ can hereby differ from the thermal flow path $\mathrm{L}, \mathrm{L}_{\mathrm{h}} \geq \mathrm{L}$, as in a cooling tube for example.

The pressure change at the beginning and end of the heat transfer surfaces is due to a change in the cross section and a change in velocity determined by Bernoulli for liquids and gases,

$\varsigma_{I, \text { in }}=1-\sigma^{2}$

being,

$\varsigma_{I, \text { out }}=\sigma^{2}-1 ; \quad$ where, $\sigma=\frac{\text { free flow area }}{\text { total face area }}, \quad \sigma \leq 1$

where $\sigma$ is the opening ratio of free surface to total surface. A constant fluid density is a prerequisite for application of these equations.

On account of the change in temperature $\Delta \mathrm{T}$ along the flow path, an additional variation between the inlet and outlet densities occurs in case of gases. If the gas is considered to be ideal, then the pressure loss arising due to it is calculated as

$\varsigma_{I, \text { thermal }}=2 \cdot \frac{\Delta T}{T_{m}}$

On considering the total apparatus, the individual components must be added for determining the total pressure loss momentum. In case of liquids with constant density, the pressure changes at the inlet and outlet are eliminated; pressure loss due to momentum changes is zero.

In case of gases, the changing density is considered and the total pressure loss momentum for ideal gases is calculated as

$\varsigma_{I, g a s}=\frac{\Delta T}{T_{m}} \cdot\left(1+\sigma^{2}\right)$ 
The determination of frictional pressure drops and pressure loss due to turbulences is treated differently for smooth and finned flow paths. However in each case, the coefficients are given as a function of the Reynolds number Re.

$\psi=f(R e)$

As for the case of thermal calculation, the behavior of the pressure loss depends on the heat exchanger flow type.

\subsection{Dimensionless number}

The relation between dimensionless numbers is largely studied, as presented in a whole chapter in [2]. To better characterize heat exchangers heat transfer $(\mathrm{Nu})$ and pressure drop $(\Psi)$, models for laminar, turbulent and also transition flows are specially studied in [1] and applied in MAHLE Behr development system.

\subsubsection{Heat transfer characterization}

The dimensionless numbers used in this method are:

$R e=\frac{\dot{m} D_{h}}{\eta_{m}}$

Where, Re is the Reynolds number, $\dot{m}$ the mass flow density, $\mathrm{D}_{\mathrm{h}}$ the hydraulic diameter, $\eta_{m}$ the dynamic viscosity of the fluid at the mean temperature.

$N u=\frac{\alpha_{m} \cdot D_{h}}{\lambda}$

$\mathrm{Nu}$ the Nusselt number, $\alpha_{\mathrm{m}}$ heat transfer coefficient of the fluid at the mean temperature, $D_{h}$ the hydraulic diameter, $\lambda$ the thermal conductivity of the fluid.

$\operatorname{Pr}=\frac{\eta \cdot c_{p}}{\lambda}$

Pr the Prandtl number, $\eta$ the dynamic viscosity of the fluid, $c_{p}$ the specific heat of the fluid, $\lambda$ the thermal conductivity of the fluid.

Those numbers are used to define the heat transfer behavior for each different heat exchanger type. For example, in case of heat exchangers with turbulators, the description of heat transfer can be made by the equation:

$N u=C_{1} \cdot\left(R e^{C_{2}}+C_{3}\right) \cdot P r C_{4}$

\subsubsection{Pressure drop characterization}

The dimensionless numbers used in this method are divided in two groups: 
Frictional pressure drop

$$
\begin{aligned}
& \varsigma_{\text {fric }}=\psi \cdot \frac{L}{D_{h}} \\
& \psi=C_{5} \cdot R e^{C_{6}}
\end{aligned}
$$

Pressure drop at inlet (contraction) and outlet (expansion)

$$
\varsigma_{i, o}=C_{7}
$$

The coefficients $\mathrm{C}_{1}$ to $\mathrm{C}_{7}$ should be determined for laminar and turbulent flow. Those coefficients are well known for a large amount of heat exchanger and presented in [1]. All technologies of MAHLE Behr heat exchangers have those coefficients well defined and calculated. New parts produced based on this well defined technologies can then be compared or validated using this functions. The way to experimentally determine those coefficients is shown in chapter 3.

\section{TEST BENCHES}

The thermal performance and pressure drop test bench in Jundiaí (Brazilian MAHLE Tech Center) is schematic presented in Figure 1. This test bench was designed to perform this performance evaluation, characterizing the heat transfer and pressure drop of the tested samples.

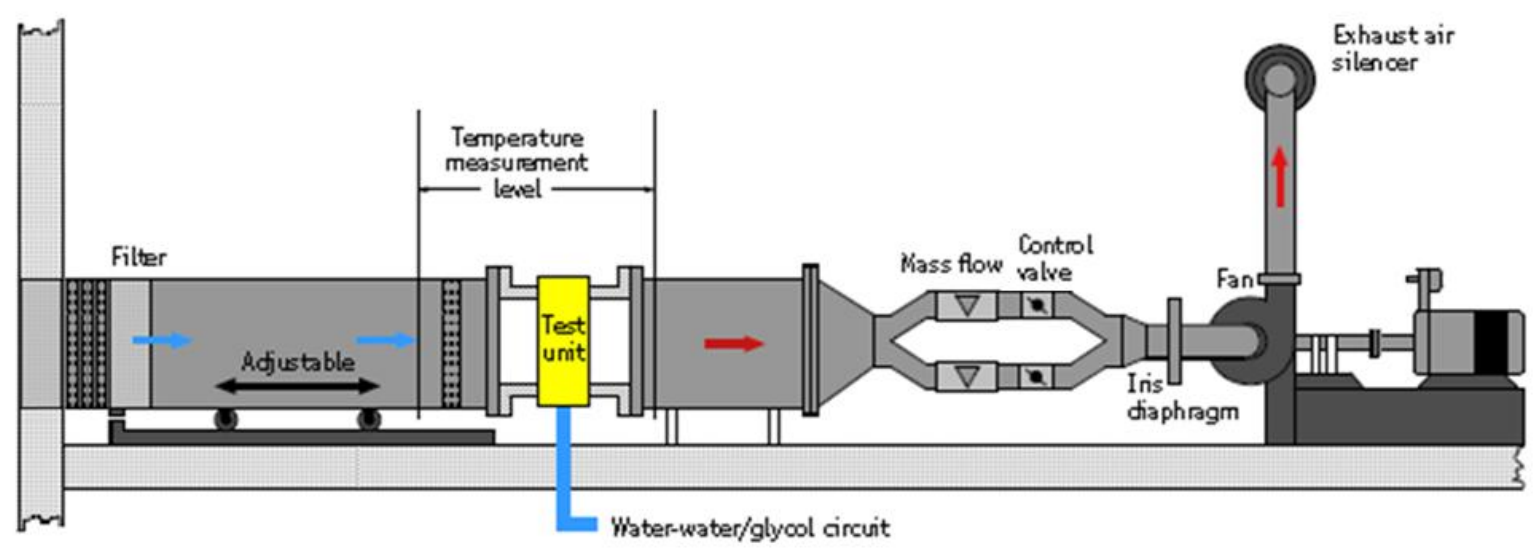

Figure 1 - Test bench schematic overview.

The test bench project was developed by the company specialists and modeled to the Brazilian reality. The construction of the test bench and its implementation was made in a multidisciplinary and multicultural team. Specialists from other locations and different suppliers worked together to implement the project.

The main activities of this test bench are:

- Test new technologies proposals, so called research elements.

- Evaluate prototypes, characterizing all kind of samples, normally delivered to the customer for a specific application.

- Validate new design concepts, at the very beginning of the project. 
- Proof the first produced samples, validating a new production line.

- Perform constant quality review at the normal production samples, named layout inspection.

- Benchmarking activities.

2.1. Test bench design focused in thermodynamic model assumptions

To ensure that all assumptions made for the thermodynamic model are fulfilled, the test bench project setup and operation must be done focused in the topics named in section 1.1. Each of them is presented here:

\subsubsection{Steady state operation}

The control of the main variables must be done properly, as described in the following paragraphs. The operating point used to generate the thermodynamic model must be acquired just after all the stabilization conditions are fulfilled.

\subsubsection{No sources or sinks of the material flows in the element itself}

Test specimen setup must ensure that no other heat source exists between the tested sample and the measurement sensors. Thermal insulation and correct stabilization time (steady state condition) is essential to achieve this target.

2.1.3. The only parameter that changes enthalpy of the streams is the heat flux that is transferred. No heat losses to the surroundings, kinetic either potential energies are considered

The specimen setup must isolate the tested sample from any interference of the environment. For example, heat losses through conduction from the tested sample to the test bench metallic components.

2.1.4. No mixing of the various material flows in the element

No leakage in the test specimen is allowed.

2.1.5. Thermal and hydraulic functions of both sides of the element are known completely

The sample drawing should be known. In case of benchmark test, also a metallographic analysis can be performed.

2.1.6. Homogenous distributions of the temperature (and the mass flow) at the inlet cross section.

A previous analysis of the heat exchanger type is done and the test bench setup is correctly prepared. For example, the measurement cross section should not be asymmetric in terms of mass flow and heat flow.

2.2. Test bench control and automation 
The test bench control and automation design concept is presented in the Figure 2. It can be divided in three main groups: hot water bench, responsible to provide water or water/glycol mixture in specific temperature and volume flow controlled conditions $\left(\mathrm{T}_{\text {in }}\right.$ and $\mathrm{V}$ ), and also information about temperature and pressure $\left(\mathrm{T}_{\text {out }}, \mathrm{P}_{\mathrm{in}}, \Delta \mathrm{P}\right)$; component wind tunnel, controlling the air mass flow $(\dot{m})$ and also with specific sensors for temperature profiles and pressure $\left(\mathrm{T}_{\text {out }}, \mathrm{P}_{\mathrm{in}}, \Delta \mathrm{P}\right)$; climatic condition sensors for atmospheric pressure, ambient temperature and relative humidity $\left(\mathrm{T}_{\mathrm{AMB}}, \mathrm{P}_{\mathrm{AMB}}\right.$, $\mathrm{RH})$.

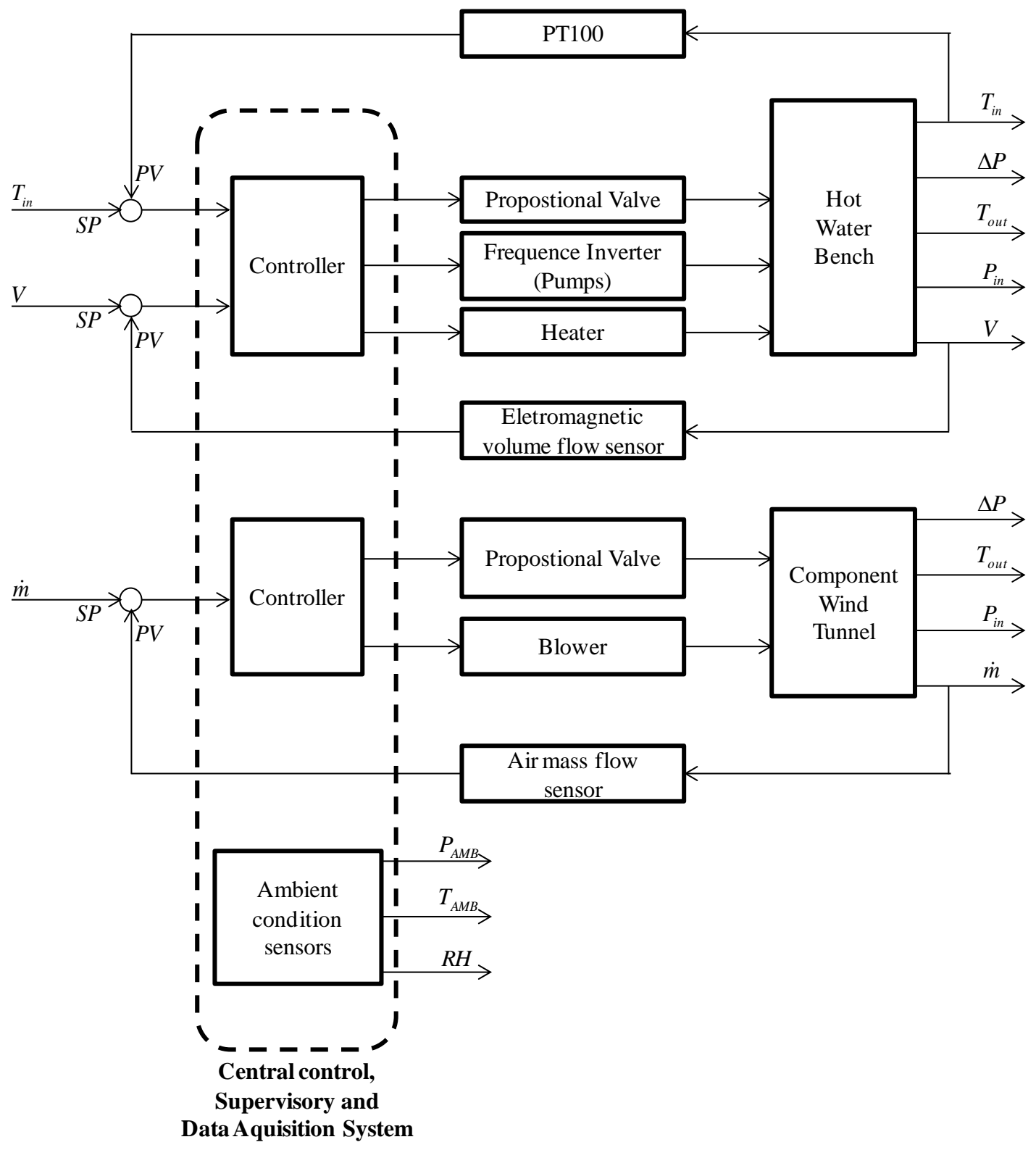

Figure 2 - Test bench control block diagram.

The data acquisition software is also an internal global project at MAHLE Behr. It was developed to preserve the same calculation methodology, precision and basic information in all test benches used in the group companies. The calculation is aligned with BISS and projected to allow a real time response. 
One of the most important advantages in using this system is the central material property data bank. The same data bank used by BISS, allows a really reliable operation, from the advanced engineering until the automatic test bench level.

The volume flow and the mass flow closed loop controllers were designed to avoid overshoot, as shown in Figure 3 and Figure 4. An overshoot in the flow causes a peak pressure in the system and can damage the tested sample.

The temperature closed loop control step response is similar to a second order under damped system. As can be seen in Figure 3. In the case of temperature, the variation of this controller is not as problematic as in case of pressure. To ensure the steady state conditions the system must wait for a certain amount of operating time inside the allowed tolerances conditions.
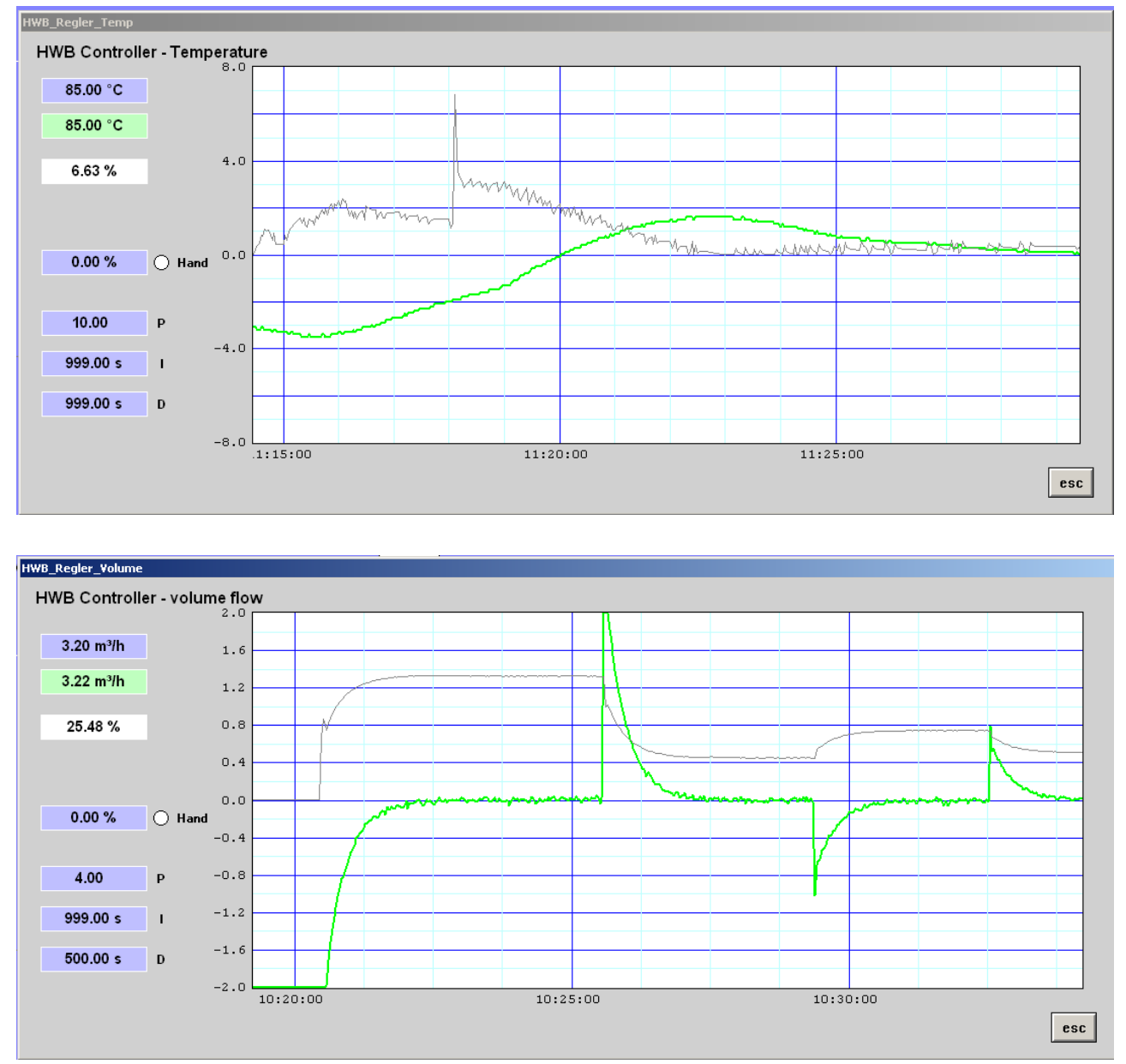

Figure 3 - Hot water bench response for temperature and volume flow control. 


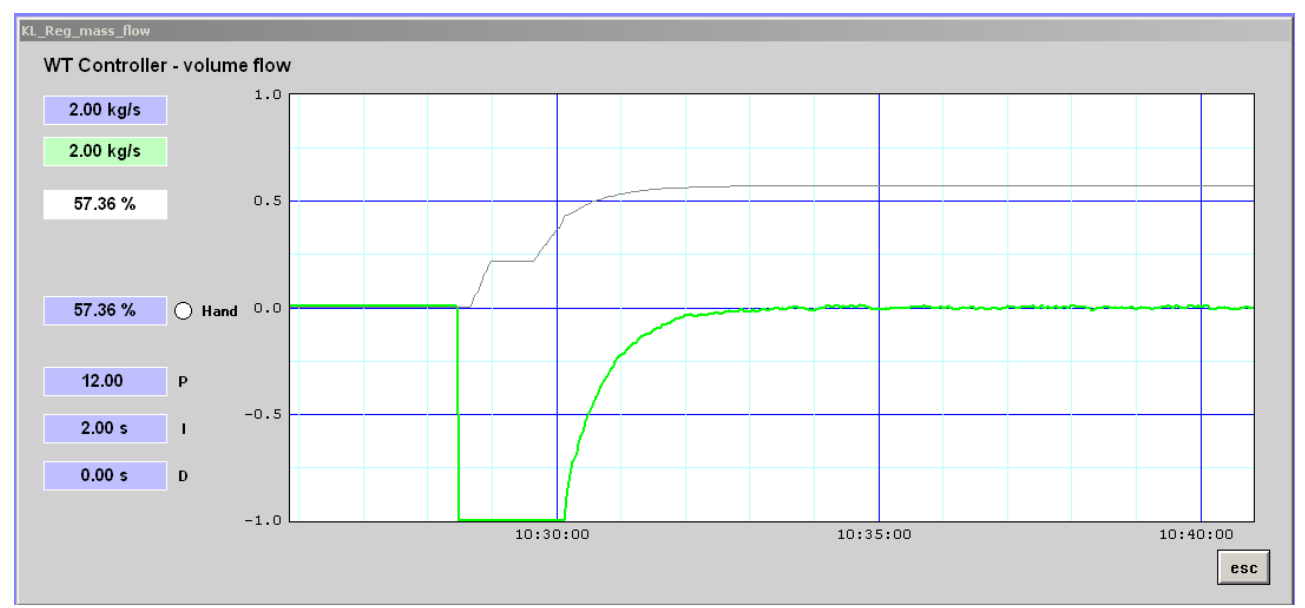

Figure 4 - Component wind tunnel response for mass flow control.

An indicator of the test quality and also one of the most important monitored values during the test bench operation is the thermal balance. The thermal balance is defined in percentage and represents the deviation of the thermal power calculated from one side from the other side (in case of a water radiator, one side is the water/glycol flow and the other the air flow). This value should be below $3 \%$.

\subsection{Test bench global certification program}

An actual strict test bench validation program is performed to ensure the quality of the data found in the central data base system. Results deviation, repeatability and reproducibility are worldwide controlled. A schematic overview of the activities and targets involving this process is presented in Figure 5.

This certification program has standardized the calibration procedures, test equipments, tests procedures and staff qualification. With the same level of standards, all locations can perform comparison measurements to correlate their results with all other test benches. This process is done periodically to ensure the worldwide testing quality.
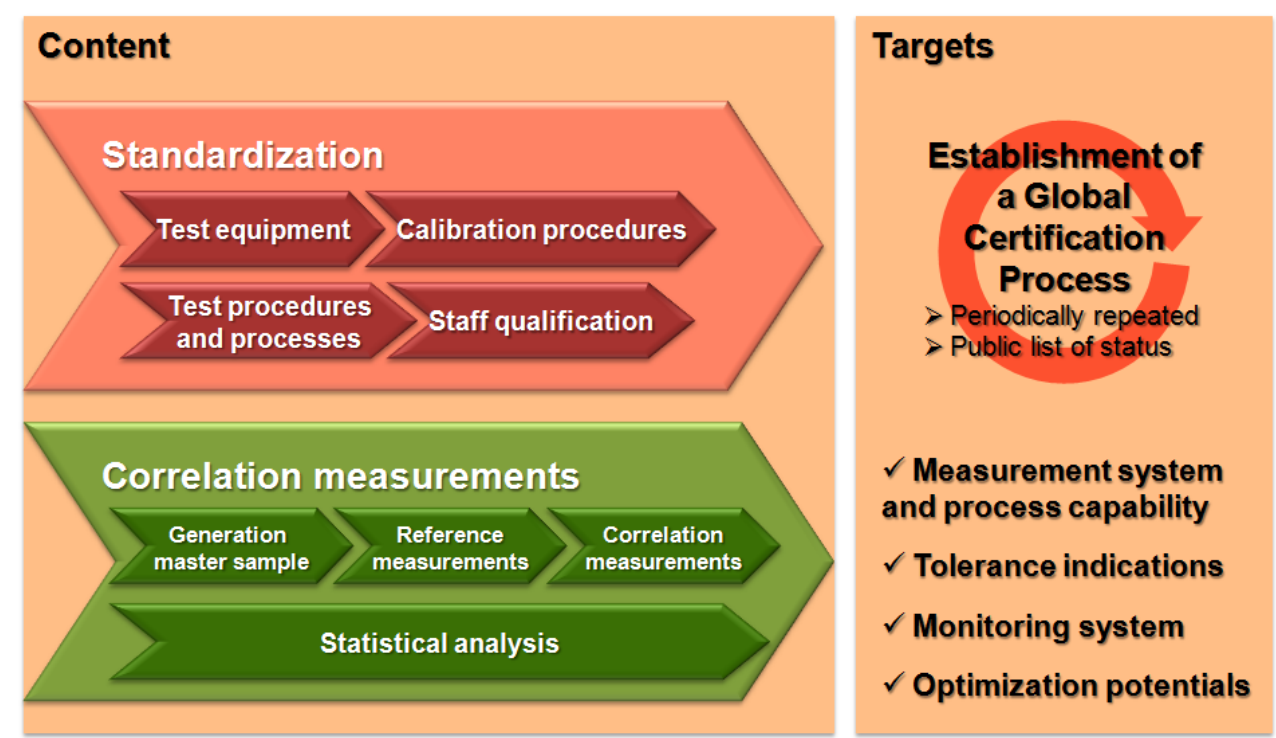

Figure 5 - Global test bench certification process. 


\section{EXPERIMENTAL DATA ANALYSIS METHOD}

The goal of the experimental data analysis method is to obtain the dimensionless numbers, as presented in section 1.4, as coefficients from $C_{1}$ to $C_{7}$. The experimental data, obtained from the measurements in the test bench, presented in section 2 , is analyzed with the method introduced in this section.

The single phase flow heat exchangers have their sides analyzed individually. What means, one of the function side is taken as reference, either with information of previous tested samples or from the thermodynamic theory for the specific heat transfer flow type. This process is then done for the other side, taking the first one as reference. An iterative process is normally performed, in order to increase the precision of the results.

If the functions of both sides of the heat exchanger are unknown, there are methods of combining different test data sets with different fluids to determine these functions.

The method is schematically summarized in the following steps:

Step 1: Measurement test data rig acquisition.

Mass flow, volume flow, temperatures and pressures. As presented in Figure 2.

Step 2: Characterization of independent sides.

$\mathrm{Q}, \Delta \mathrm{P}_{1}, \Delta \mathrm{P}_{2}, \Delta \mathrm{T}_{1}, \Delta \mathrm{T}_{2}, \Delta \mathrm{T}_{\mathrm{e}}, \Phi, \mathrm{W}_{1}, \mathrm{~W}_{2}, \mathrm{~W}_{\min }, \mathrm{W}_{\max }$.

Those equations are presented in sections 1.2 and 1.3. They are presented as the first steps of those calculation. Just the variables that can be obtained directly from the test rig data, the sample dimensions and flow type information.

Step 3: Analyze one side, considering the other as input.

Calculate numbers defined in section 1.2 to evaluate the heat transfer quality. Calculate numbers defined in section 1.3 to evaluate the pressure drop as described in this section. Other coefficients, which are not presented in this work, should also be calculated at this step, they evaluate the fin efficiency, convective heat transfer, thermal effectiveness and other key characteristics.

With the coefficients calculated until here, special diagrams are plotted and help analyzing the heat transfer, and the project optimization potentials. One example is the $\Phi$ versus NTU diagram, presented in [1] and used to guide the development of new technologies.

Step 4: Create dimensionless functions for the analyzed side.

Define coefficients $\mathrm{C}_{1}$ to $\mathrm{C}_{7}$, as defined in 1.4 for laminar and turbulent flow (transition flow can also be determined).

Step 5: Repeat the steps 2 to 4, for the non analyzed side. 
Using the data obtained in the previous steps as reference, the non analyzed side should be also evaluated and characterized by this method.

An example of the result of this analysis method is shown in Figure 6.

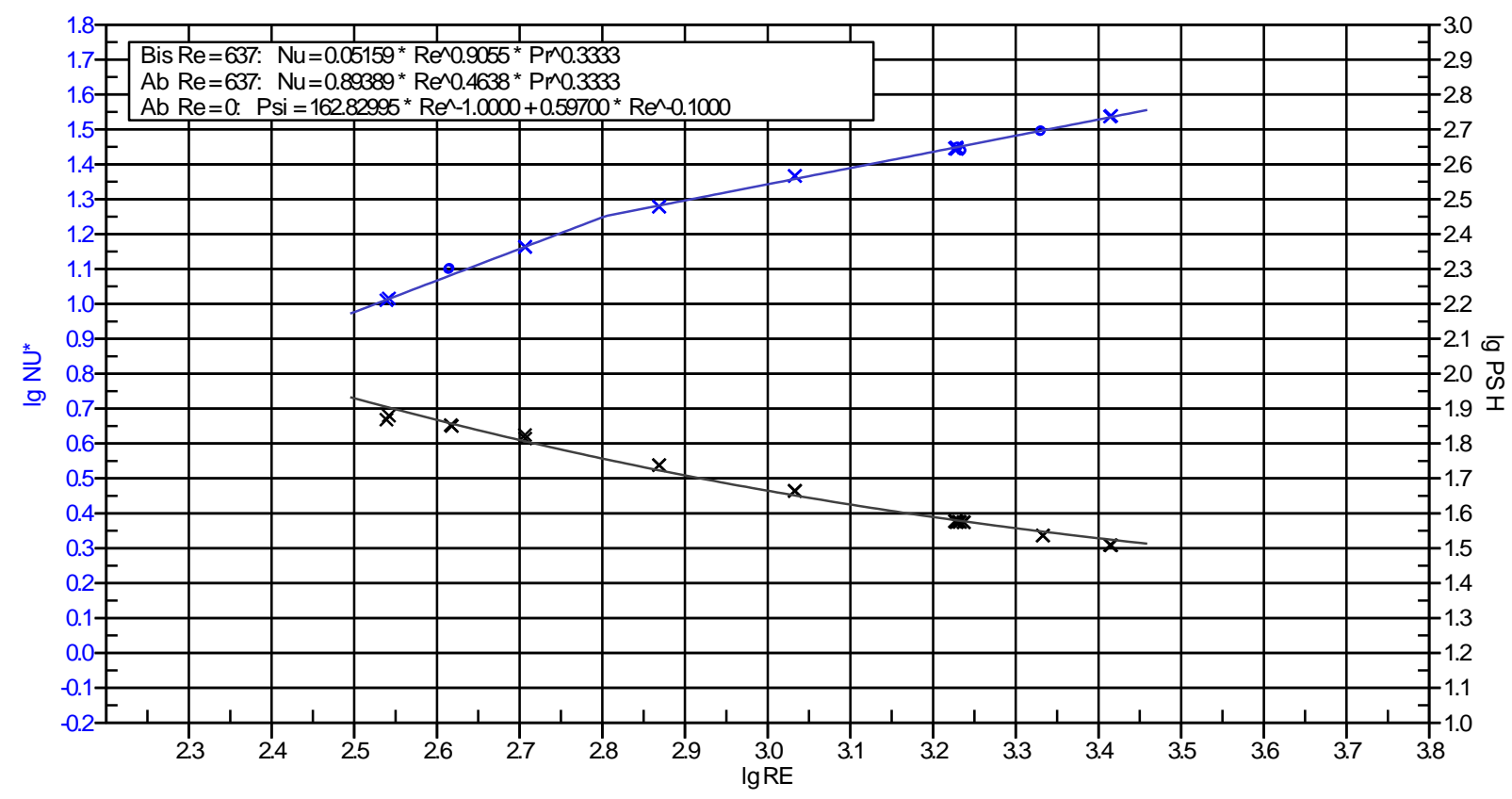

Figure 6 - Dimensionless function determination, example of a construction system function.

\section{SIMULATION TOOL SYSTEM}

The simulation system used in MAHLE Behr worldwide (BISS) was developed by the company to simulate vehicle thermal management systems, initially working with single phase heat exchanger; it was expanded to simulate different systems such as the Rankine system architecture and the impact of the working fluid choice [3].

Figure 7 shows schematically the BISS data management and its usage. A global data base is used to standardize the information used by all users worldwide. Some tools were developed to evaluate test bench data and validate the mathematical model, for the case of single phase flow heat exchanger; this process is presented in this work. Although the main use of the simulation system is the generation of the so called System Topologies. Using 2D and 3D elements (as shown in Figure 8 and Figure 9), the users can input actual boundary conditions and element dimensions to evaluate their concepts. 


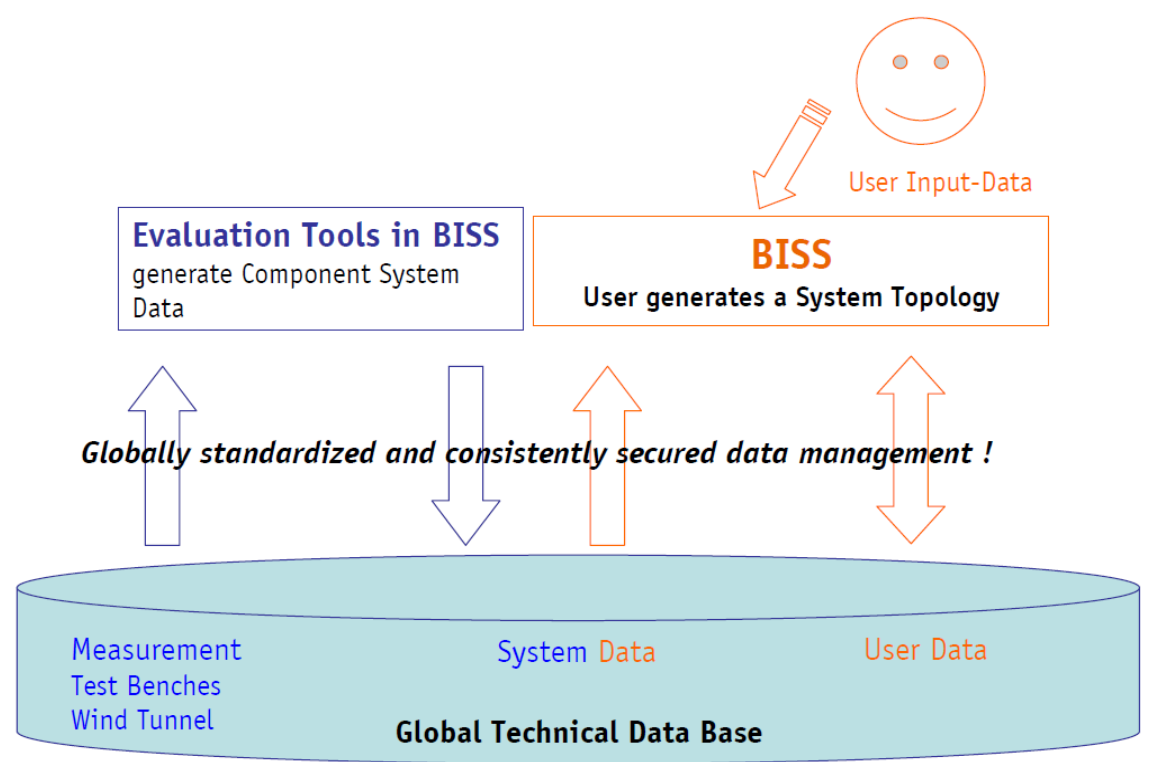

Figure 7 - Typical BISS Data Management [3].

The use of the simulation system to develop new cooling module applications and component design can be seen in [6], where the integration of the thermodynamic analyzing tool is done with the Finite Elements Analysis (FEA) to study also vibration, thermal shock and other structural phenomena.

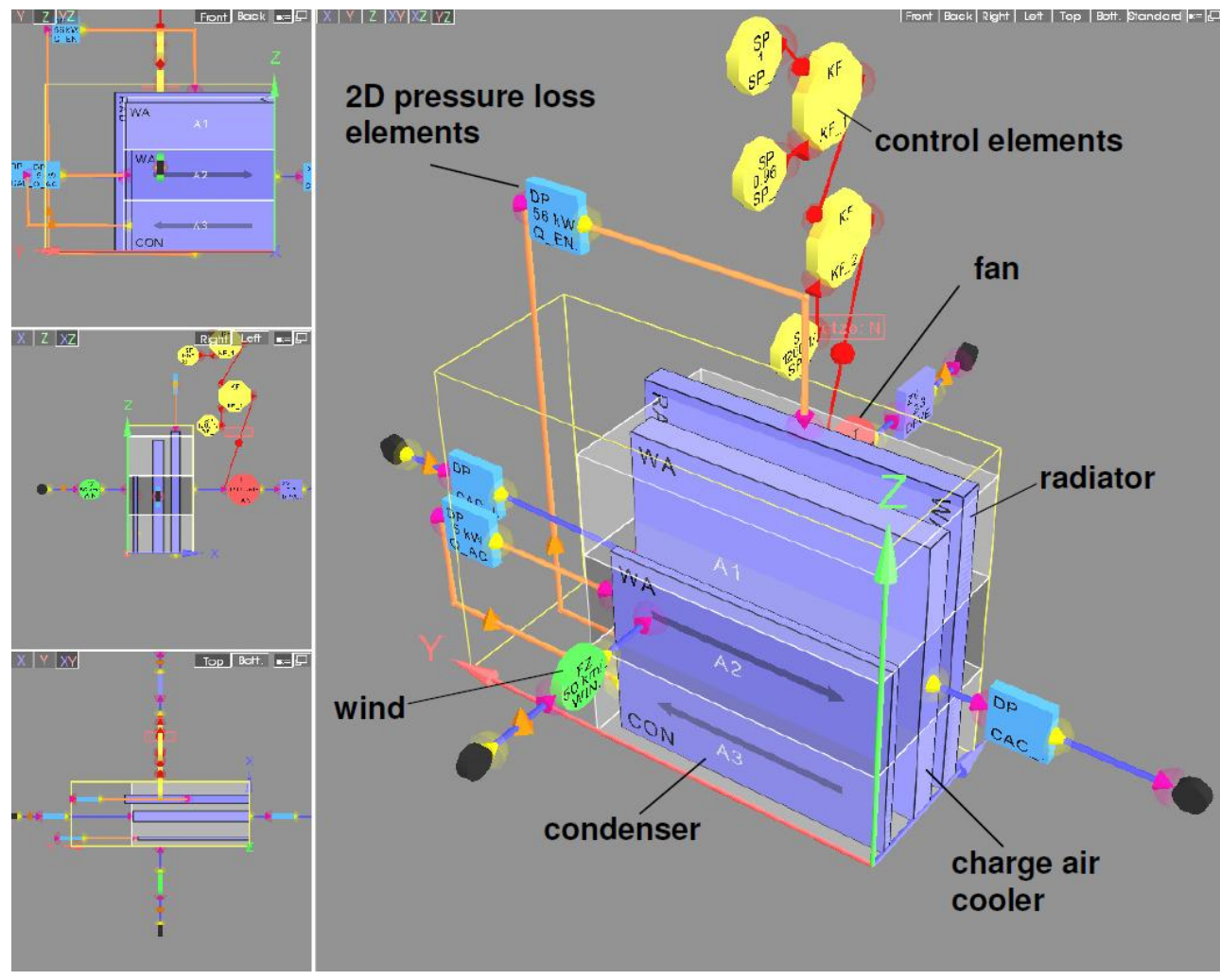

Figure 8 - Complete cooling module in the BISS 3D modeler including 2D elements for the cooling cycle [3]. 


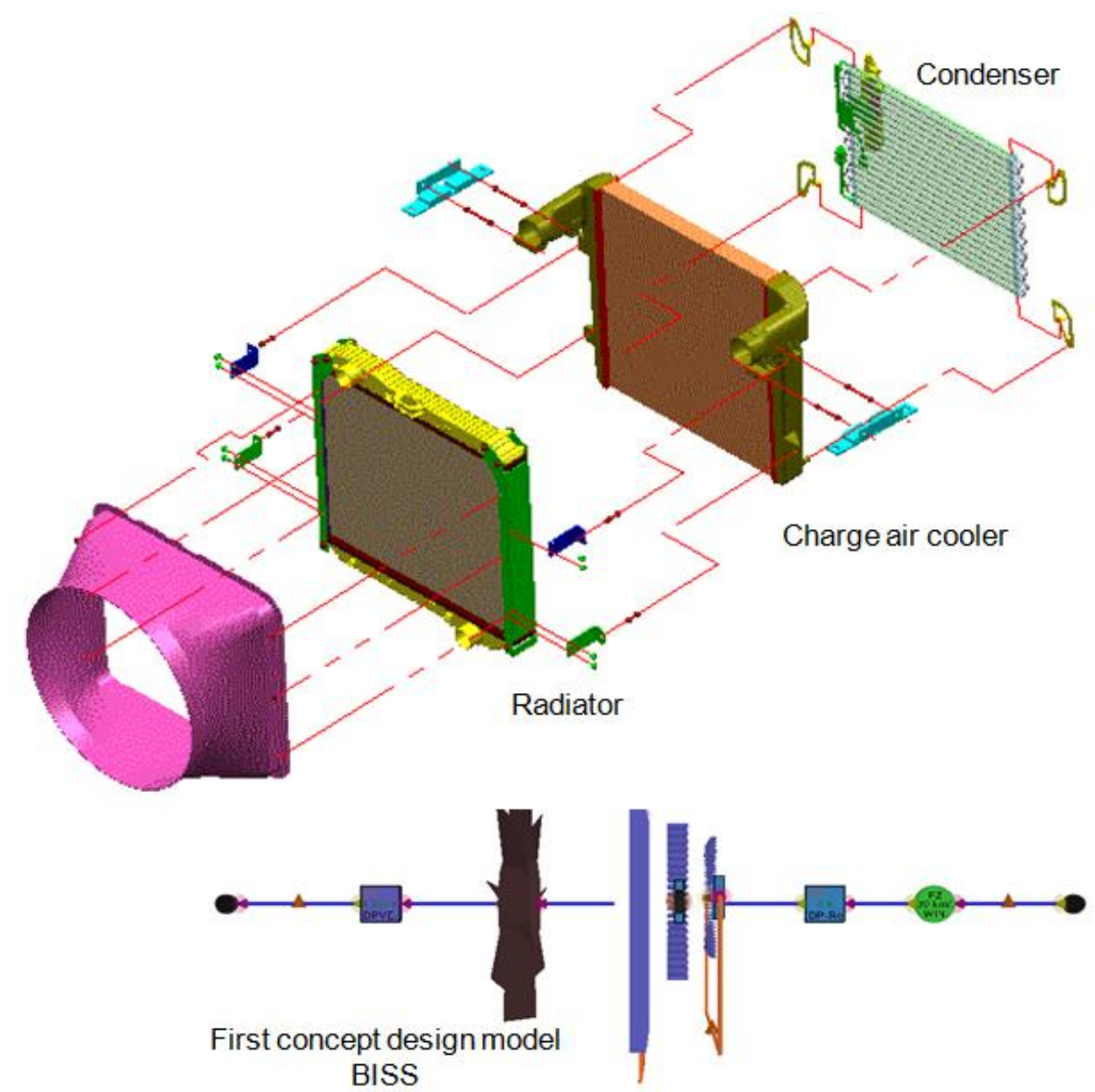

Figure 9 - 2D BISS Topology shown with the real cooling module concept [6].

The methodology to design a new application, based on the customer expectation of thermal capacity for different operating points is described in [7]. This methodology is based on an iterative analysis, initiating with the system needs and adding real data and information based on other application experience and test bench data.

\section{CONCLUSIONS}

The methodology of single phase flow heat exchanger design based in dimensionless numbers is introduced in this work. A case study of how the theory can be applied in the day by day product development of a global company is the core of this work.

The test bench implementation and its use in the product development process were discussed. The test data management and standardization are essential to sustain a modelbased design method. The large use of the test bench is also helpful, not just in new product development, but also in single sample characterization and plant quality operation.

The advantages and disadvantages of the method presented in this work are exposed here:

Advantages:

- No need to adjust mass flows, inlet temperatures and pressures during test rig tests to exact values.

- Saves a lot of time at test rig. Test rig capacity can be much better exploited. 
- With Nusselt and $\psi$-functions exact inlet conditions can be simulated. And not just the points measured in the test bench can be used.

- Extrapolation is possible, that means, if heat exchanger is too large for test rig performance range a "cutout"-measurement can be done. Knowing the thermal transfer characteristics from one part of the heat exchanger, all the heat transfer can be precisely calculated.

- With a multitude of test data sets, better average dimensionless functions for simulation of heat exchangers can be created.

- Get more statistical certainty for layout of heat exchangers.

Disadvantages:

- Trained personnel needed with simulation and thermodynamic specific knowledge.

- Analysis of data needs some time (Create dimensionless functions, perform simulations and write reports).

- Process of using dimensionless functions is more complicated in comparison with presenting directly the test bench data. Sometimes methodology training must be done to discuss validation process with new customers, suppliers or employees.

- If there is no sufficient basic knowledge of heat exchanger simulation, this can be tried in vain. As every simulation tool, the application success depends a lot on the knowledge of its users.

The model-based design method, validated through test bench data, is strategic to lead the fast development process. Reduction of the time to market and the improvement of plant quality are key processes to a successful product development. The creation and maintenance of a validation and simulation team is essential for this process.

\section{REFERENCES}

[1] KAYS, William Morrow; LONDON, Alexander Louis. Compact Heat Exchangers. 3.

Ed. Stanford: McGraw-Hill, 1998.

[2] STEPHAN, Peter; et al. VDI Heat Atlas. Düsseldorf: Springer, 2010.

[3] GNEITING, Ronald; HECKENBERGER, Thomas; SAUER, Christoph. 2 Virtual

Thermal Management in Cars - Requirements and Implementation. 6th FKFS

Conference: Progress in Vehicle Aerodynamics and Thermal Management, Stuttgart, 2007

[4] WILKEN, Prof. Dr. Harald. Berechnungsgrundlagen für Wasser/Luft-Kühler.

Stuttgart: BEHR Report 71/622, 1971.

[5] FAUSER, Dr. Jürgen. Thermodynamic Modeling of Elements. Stuttgart: MAHLE Behr Report, 13.11.2012.

[6] NAKAMURA, Helio; LIMA, Renon; STUCK, Hans-Martin. Presentation in SAE Test and Simulation Symposium. São Paulo, 2010

[7] MIYAUCHI, Edison; LIMA, Renon; PEREIRA, Diego. Integração físico-virtual no desenvolvimento de módulo de arrefecimento. $9^{\circ}$ Símposio SAE Brasil de testes e simulações. São Paulo, 2011. 